\title{
A Case Study of Mesospheric Wave Periods and Horizontal Structures over a Low Latitude Station, Allahabad (India)
}

\author{
N. Parihar ${ }^{1}$, A. Taori ${ }^{2}$, V. Kamalakar ${ }^{3}$ \& S. V. B. Rao ${ }^{3}$ \\ ${ }^{1}$ Dr. K. S. Krishnan Geomagnetic Research Laboratory, Allahabad (U.P.), India \\ ${ }^{2}$ National Atmospheric Research Laboratory, Gadanki, India \\ ${ }^{3}$ Sri Venkateswara University, Tirupati, India \\ Correspondence: N. Parihar, Dr. K. S. Krishnan Geomagnetic Research Laboratory, Allahabad (U.P.) 221505, \\ India. Tel: 91-945-560-1469. E-mail: navindeparihar@gmail.com
}

Received: April 12, 2012 Accepted: April 27, 2012 Online Published: August 2, 2012

doi:10.5539/esr.v2n1p1 URL: http://dx.doi.org/10.5539/esr.v2n1p1

\begin{abstract}
We report the measurements of short period gravity waves with the help of all sky imager operated at $\mathrm{OH}$ nightglow wavelenghts during 21-22 and 23-24 April 2009 from Allahabad (25.5 $\left.\mathrm{N}, 81.9^{\circ} \mathrm{E}\right)$, India. We note persistent oscillations on both the nights with wave periods ranging from 0.4 to 1.5 hours. To quantify the zonal and meridional scales of these waves, we analyze the intensity variability noted in zenith angles $30^{\circ}, 15^{\circ}$ and $0^{\circ}$ in East, West, North and South directions. We find the wavelengths of observed waves to vary from 40 to 100 $\mathrm{km}$. We discuss these observed wave properties in connection to their importance in global circulation of upper atmosphere.
\end{abstract}

Keywords: airglow, mesosphere, gravity waves

\section{Introduction}

Gravity waves and tides are the important dynamical drivers of the mesosphere-lower thermosphere (MLT) region. Gravity waves are created by the action of gravity on the density variations in the stratified troposphere from passage of wind over topographic structures, frontal, dust-storm and convective activity, and wind shears and have periods typically ranging between few minutes to 3 hours (e.g., Das et al., 2011; Taori et al., 2012a and references cited therein); whereas, tides are a consequence of heating due to absorption of solar infrared and ultraviolet radiation by the tropospheric water vapour and stratospheric ozone, respectively (Forbes and $\mathrm{Wu}$, 2006 and references cited therein). These waves propagate upwards as well as horizontally with the amplitude growing with height (due to negative density gradient of the atmosphere). At mesospheric altitudes, their amplitudes grow many-folds and they become convectively unstable (thereby attaining the saturation limit). Ultimately they break and dissipate momentum and energy to the background atmosphere (Hines, 1960). As such, these upward propagating gravity wave and tides strongly govern the atmospheric circulation, thermal structure and chemical composition at the MLT heights through the dissipation of energy and momentum (Fritts \& Alexander, 2003). An assessment of the effects of these gravity waves in global circulation models is difficult because firstly, they are highly variable (i. e. they may exist on a given night, while may not be present on the other one), and secondly, the observations of their periodicity, horizontal and vertical wavelength is difficult. In particular, the short period gravity waves having periodicity less than $3 \mathrm{~h}$ lack sufficient observations owing to the required high time resolution. Of late, the ground-based, satellite-borne and in-situ measurements have addressed enormously to our understanding of gravity waves and their profound influence in the MLT variabilities.

Among other ground-based techniques (viz. VHF/ UHF/ MF/ MU/ Meteor radars, falling spheres and lidar instrumentation), airglow observations have been widely used to study the gravity wave and tidal features at the MLT altitudes (e.g., Taori et al., 2005; Guharay et al., 2008; Taori \& Taylor, 2010). On course of their propagation through the airglow emission layer, gravity waves or tides induce variability in density of the reacting species and temperature which in turn affect the rate of the photochemical reaction responsible for airglow process. In summary, the perturbations due to passage of gravity waves or tides are reflected as wavelike modulations in the airglow emission intensity. After the advent of CCD based detectors and the advances in 
observational techniques, the imaging observations have proved an excellent tool to study the propagation characteristics of the small-scale gravity waves and their temporal evolution during recent times (due to the fact that the sequential images captured by an imaging system provide excellent track of gravity-wave events). As for example, Medeiros et al. (2005) presented a comprehensive report on the horizontal characteristics of gravity waves observed over three different locations in South America. Wrasse et al. (2006) studied the gravity wave propagation through atmosphere using imaging observations and reverse ray-tracing technique. Also, several reports now exist on the detection of planar wave fronts and non-linear wave events such as mesospheric bores and wall identified with the help of airglow imaging (Shiokawa et al., 2000; Smith et al., 2006; Scheer \& Reisin, 2010).

With reference to such studies in Indian subcontinent, there had been isolated studies of gravity waves at the MLT heights with simple airglow photometers (Taori \& Parihar, 2011; Taori et al., 2012b) and airglow imagers (Mukherjee et al., 2010; Lakshmi Narayanan et al., 2010). Using imaging observations, Mukherjee et al. (2010) studied the effects of wind filtering on the propagation of gravity waves over Allahabad $\left(25.5^{\circ} \mathrm{N}, 81.9^{\circ} \mathrm{E}\right)$, India; and Lakshmi Narayanan et al. (2010) presented the observations of large- and small-scale gravity wave features in $\mathrm{OH}$ nightglow images associated with the convective instability over Tirunelveli $\left(8.7^{\circ} \mathrm{N}, 77.8^{\circ} \mathrm{E}\right)$. Using nightglow photometry, Parihar et al. (2011) reported the observations of gravity waves and tides in OI $557.7 \mathrm{~nm}$ emission intensity and $\mathrm{OH}$ temperatures; while, Taori et al. (2012b) reported the observations of gravity waves in $45-90 \mathrm{~km}$ altitude regime over Gadanki $\left(13.8^{\circ} \mathrm{N}, 79.2^{\circ} \mathrm{E}\right)$, India using simultaneous airglow and Rayliegh lidar measurements. However, the simultaneous measurements of horizontal wavelengths and periodicity of gravity waves have not been reported till now. Motivated by this fact, a case study of airglow imaging observations carried out on 21-22 and 23-24 April 2009 from Allahabad (25.5 $\left.{ }^{\circ} \mathrm{N}, 81.9^{\circ} \mathrm{E}\right)$, India has been made, and this report constitutes probably the first one featuring concurrent measurements of horizontal wavelengths and periodicity. Gravity wave activity was stronger on these two nights compared to the other nights during April 2009.

\section{Experimental Set Up, Results and Discussion}

An all sky airglow imaging system (manufactured by Keo Scientific Ltd., Canada) was deployed for observations of $\mathrm{OH}$ nightglow at Allahabad $\left(25.5^{\circ} \mathrm{N}, 81.9^{\circ} \mathrm{E}\right)$, India. The imaging system comprises a fast $\mathrm{f} / 4$ all-sky telecentric lens systems (having field of view of $179^{\circ}$ ) as the optical unit, and a back-illuminated $512 \mathrm{x}$ 512 pixels CCD (Scientific grade 1, $24 \mu \mathrm{m} \times 24 \mu \mathrm{m}$, and thermoelectrically cooled to $-53^{\circ} \mathrm{C}$ ) as the photon detector. WinView software was used to control the camera. A $190 \mathrm{~nm}$ broadband optical filter $(720-910 \mathrm{~nm})$ [having a transparency of $87 \%$ and a notch at $868 \mathrm{~nm}$ \{to exclude contribution from the $\mathrm{O}_{2}(0,1)$ Atmospheric band emission\}] thermoelectrically cooled at $-25^{\circ} \mathrm{C}$ was used to monitor $\mathrm{OH}$ nightglow. Although the imager had six filters, one filter could be only operated due to software limitation. On 21-22 April 2009, the exposure and delay time was adjusted to have a cycle of 4 min, whereas, it was 2 min for 23-24 April 2009. The image processing involved a) the flat-field corrections to account for the intensities variations due to the lens curvature, b) to approximately remove the artifacts due to van Rhijn effect and atmospheric extinction c) the non-uniform pixel-to-pixel sensitivity of the CCD detector, and d) scaling to $5 \%$ to $95 \%$ of the intensity range. Assuming the $\mathrm{OH}$ emission peak to be $87 \mathrm{~km}$ and it remained unchanged during the night, the images were transformed to geographic coordinate system. In order to identify the short period wave features (mainly horizontal scales and periodicity) - firstly, the average intensity of a square bin of 16 pixel x 16 pixel of the processed image was computed along zenith, $15^{\circ}$ North, $15^{\circ}$ South, $15^{\circ}$ East and $15^{\circ}$ West; and then using this intensity information, the time series were generated for zenith and different off-zenith directions. This was followed by the calculation of the intensity deviation at a particular time by substracting the mean value during the night from the observed intensity, so as to construct a detrended series, and then Morlet wavelet analysis of this series was performed (see Torrence and Compo, 1998 for more information on Morlet wavelet analysis) to identify the harmonics present in the nightglow data as well as their phase information.

\subsection{Observations of 21-22 April 2009}

The intensity deviations (left panels) and corresponding Morlet wavelet analysis (right panels) for OH nightglow measurements on 21-22 April 2009 are shown in Figure 1. In the figure, the variability observed along zenith angles varying from $30^{\circ} \mathrm{E}$ to $30^{\circ} \mathrm{W}$ at $15^{\circ}$ interval (representing the zonal intensity variability) are plotted from top to bottom. In each plot, the signatures of short period oscillations riding over a long period nocturnal variation can clearly be seen. It is important to note here that along $30^{\circ} \mathrm{E}$, the nocturnal plot shows the intensity minima to occur at about $26.7 \mathrm{~h}$ (i.e. $02.7 \mathrm{~h}$ IST of 22 April 2009) while the plot along $30^{\circ} \mathrm{W}$ shows minima occurring near $27.0 \mathrm{~h}$ (i.e, $03.0 \mathrm{~h}$ IST of 22 April 2009) which clearly indicates the propagation of waves. The wavelet analysis of the intensity data reveals the presence of three distinct wave packets of a) $0.4-0.5 \mathrm{~h}$ wave, b) 
0.7-1.0 $\mathrm{h}$ wave and c) 1.1-1.5 h wave. Please note that the dotted black lines in the wavelet analysis represent the cone of influence.
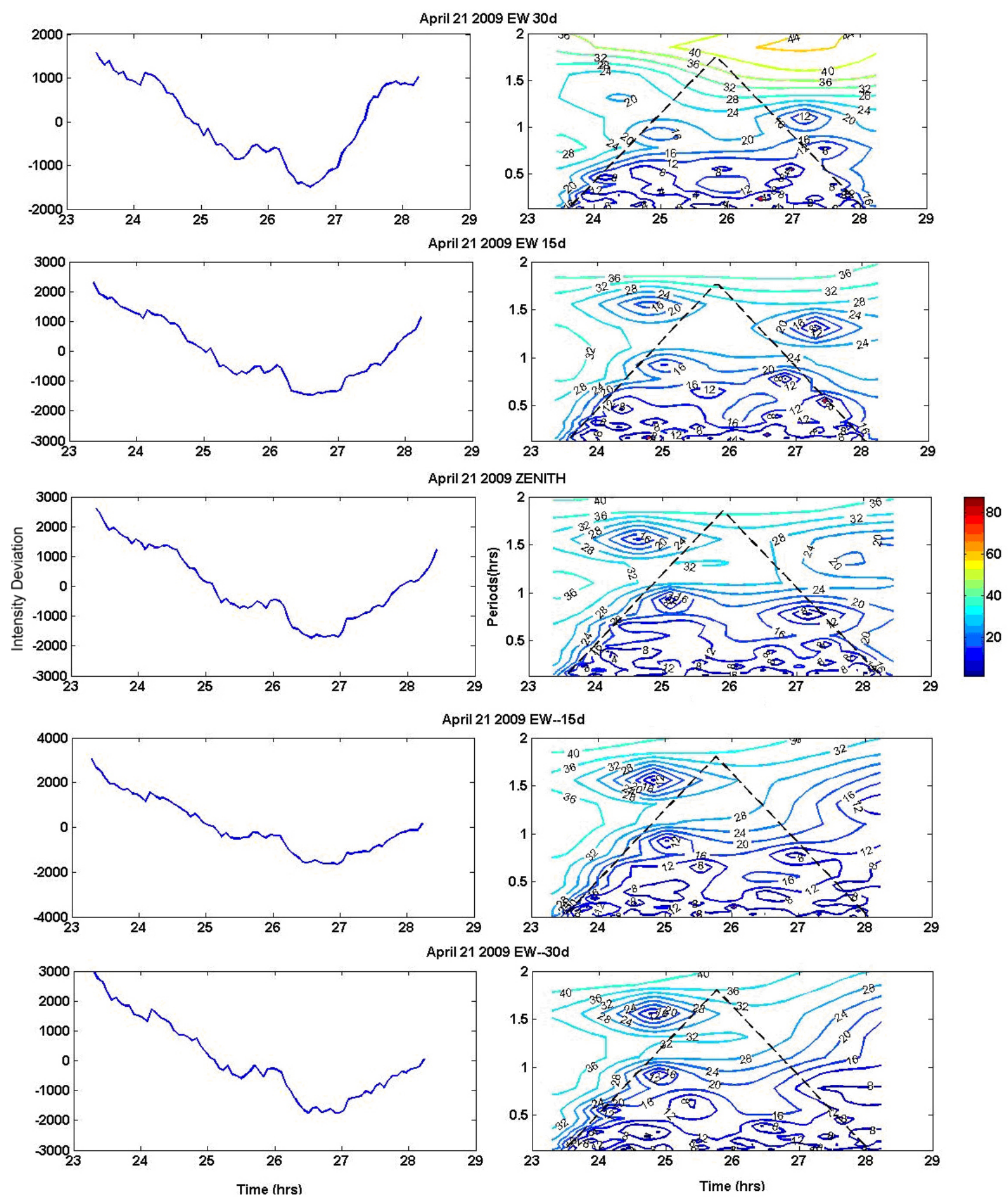

Figure 1. Mean intensity deviations (left panels) for 21-22 April 2009 and their corresponding Morlet wavelet analysis (right panels). Plotted from top to bottom are the mean intensity deviations for zenith angles $30^{\circ} \mathrm{E}$ to $30^{\circ}$ $\mathrm{W}$ at $15^{\circ}$ interval

To study the short period gravity wave feature and their zonal and meridional structures, we follow the phases of wave packets observed in the wavelet spectra. We categorize three wave packets as stated above and find out the 
time of maximum amplitudes of individual wave packet spectra and utilize this information to estimate their structures in zonal as well as in meridional direction. For example, 0.4-0.5 h wave show maximum of wave amplitudes (in wavelet spectra) to occur at about $24.1,24.3,24.5$ and $24.2 \mathrm{~h} \mathrm{IST}$ for $30^{\circ} \mathrm{E}, 15^{\circ} \mathrm{E}$, Zenith, $15^{\circ} \mathrm{W}$ and $30^{\circ} \mathrm{W}$ respectively, while; the $0.7-1.0 \mathrm{~h}$ wave show the maximum of amplitudes to occur at $24.4,25,25.1$, 25 and $24.9 \mathrm{~h}$ IST for zenith angles $30^{\circ} \mathrm{E}$ to $30^{\circ} \mathrm{W}$ at $15^{\circ}$ interval (please note that time is in continuation from the observations and therefore $24.4 \mathrm{~h}$ means $0.4 \mathrm{~h}$ IST of next day, and so on). Utilizing this information, we plot the phase of waves in Figure 2 (shown in solid squares). One may clearly see signature of wave structures in the data. To emphasis the wave structure in data, we perform a simple best-fit waveform analysis. In this analysis, a simple best fit cosine model of the following form is applied on the detrended data to determine the perturbation amplitudes:

$$
\mathrm{Y}=\mathrm{Y}_{0}+\mathrm{A}^{*} \cos [\pi(\mathrm{X}-\mathrm{Xc}) / \mathrm{W}]
$$

where, $\mathrm{Y}_{0}$ is the mean values (which is 0 in our case), $\mathrm{A}$ is the amplitude of the fitted wave of half-wavelength $\mathrm{W}$ with phase $\mathrm{Xc}$, and $\mathrm{X}$ is the space. The results of the best-fit analysis for zonal scans are shown as red solid connecting lines. One may note clearly that the $0.4-0.5 \mathrm{~h}$ waves have a zonal wavelength of $\sim 126 \mathrm{~km}$. For 0.7-1.0 $\mathrm{h}$ waves the horizontal wavelengths could not be estimated due to unclear wave-form (possibly because their horizontal wavelengths may be larger than the field of view of imager). The 1.1-1.5 $\mathrm{h}$ wave packet on the other hand shows the horizontal wavelengths to be $\sim 90 \mathrm{~km}$.

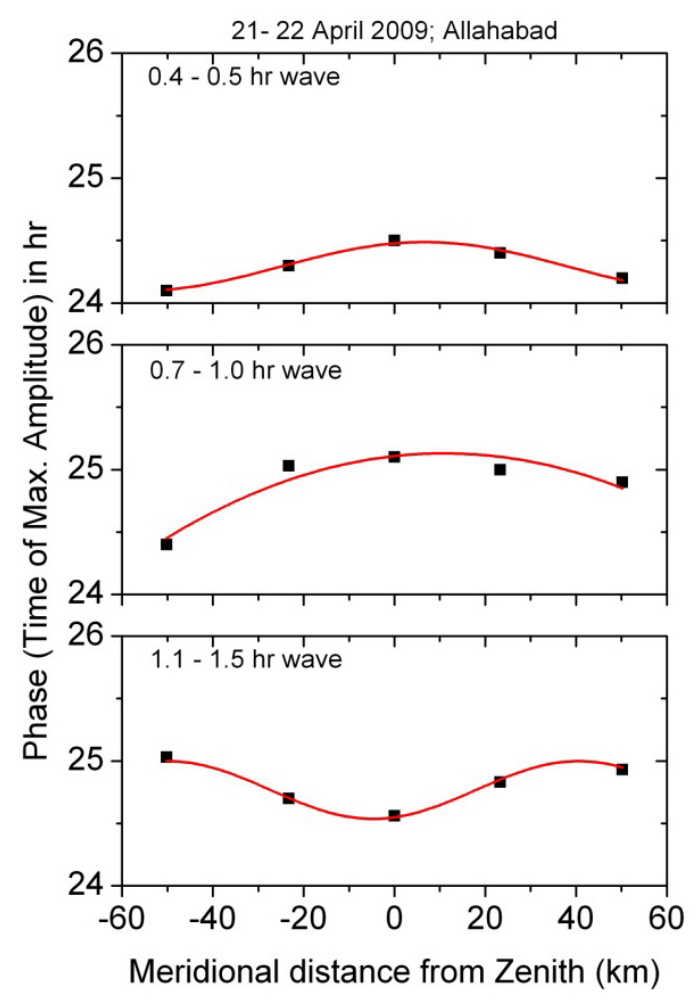

Figure 2. The phases of waves as noted in the wavelet analysis together with the best-fit cosine model analysis for zonal positions corresponding to zenith angles $30^{\circ} \mathrm{E}$ to $30^{\circ} \mathrm{W}$ at $15^{\circ}$ interval

The intensity deviations in the meridional direction (zenith angles, $30^{\circ} \mathrm{N}, 15^{\circ} \mathrm{N}, 0^{\circ}, 15^{\circ} \mathrm{S}$ and $30^{\circ} \mathrm{S}$ ) are shown in the left panels of Figure 3, while the corresponding wavelet analysis is shown in right panels. In general, the long period nocturnal variation, which exhibits minima about 2700 h, i.e. 0300 IST shows a slow progression from North to South. To find out the meridional structures in the observed short period waves, we first categorize three wave packets (as explained earlier) of 0.4-0.5 h, 0.7-1.0 h and 1.1-1.5 h periodicity band and plot the time of maximum amplitudes of these wave packets in Figure 4 (filled squares). The absence of a data for 0.4-0.5 h wave at around $22.5 \mathrm{~km}$ is because of unclear signature of this wave at $15^{\circ} \mathrm{S}$. Results of the best-fit cosine model which are shown as red connecting lines in Figure 4 are utilized to get an estimate on the horizontal scales of these wave packets. One may note clear signatures of waves with meridional wavelengths 72,199 and $106 \mathrm{~km}$ 
for $0.4-0.5 \mathrm{~h}, 0.7-1.0 \mathrm{~h}$ and 1.1-1.5 $\mathrm{h}$ waves respectively. Table 1 summarizes the observed wave features for this particular night.
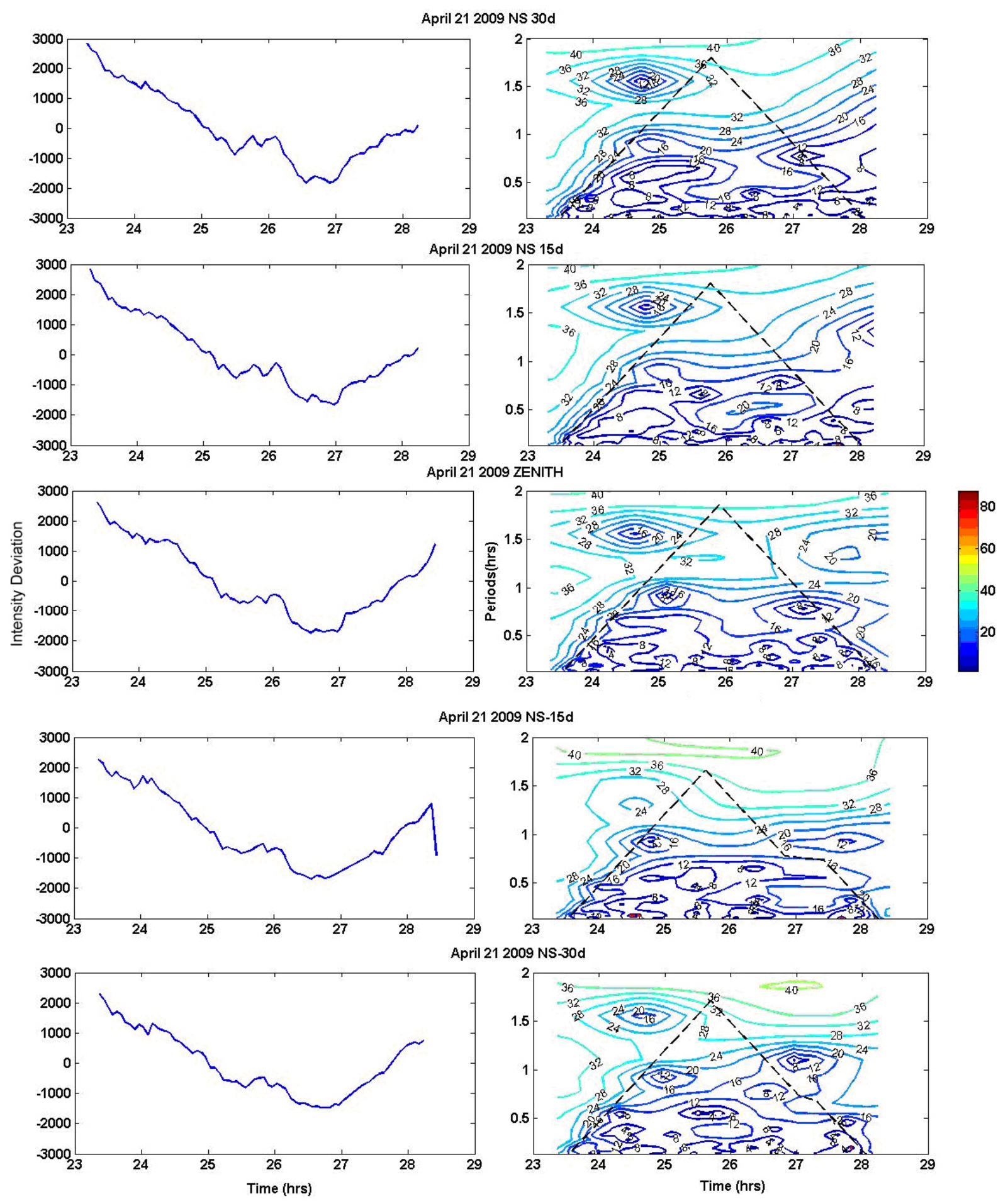

Figure 3. Same as Figure 1 but for zenith angles in meridional directions varying from $30^{\circ} \mathrm{N}$ to $30^{\circ} \mathrm{S}$ at $15^{\circ}$ interval for 21-22 April 2009 data 


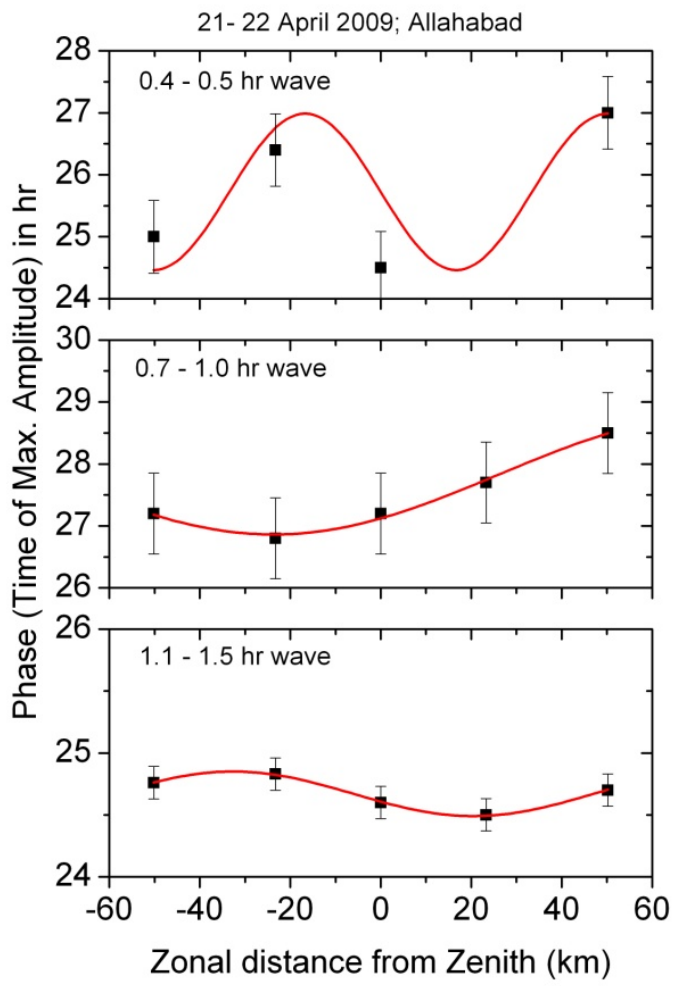

Figure 4. Same as Figure 2 but for zenith angles varying from $30^{\circ} \mathrm{N}$ to $30^{\circ} \mathrm{S}$ at $15^{\circ}$ interval for $21-22$ April 2009

Table 1. Summary of the observed harmonics present along zenith and different of zenith directions along with the time of maximum phase (here $\tau$ correspond to the periodicity of the observed wave, while the time of maximum phase is represented by $t_{m}$ ) for 21-22 April 2009

\begin{tabular}{cccccccccccc}
\hline & \multicolumn{2}{c}{ 1st wave } & \multicolumn{2}{c}{ 2nd wave } & \multicolumn{2}{c}{ 3rd wave } & \multicolumn{2}{c}{ 4th wave } & \multicolumn{2}{c}{ 5th wave } \\
\cline { 2 - 11 } Directions & $\tau$ & $\mathrm{t}_{\mathrm{m}}$ & $\tau$ & $\mathrm{t}_{\mathrm{m}}$ & $\tau$ & $\mathrm{t}_{\mathrm{m}}$ & $\tau$ & $\mathrm{t}_{\mathrm{m}}$ & $\tau$ & $\mathrm{t}_{\mathrm{m}}$ \\
& $(\mathrm{h})$ & $(\mathrm{IST})$ & $(\mathrm{h})$ & $(\mathrm{IST})$ & $(\mathrm{h})$ & $(\mathrm{IST})$ & $(\mathrm{h})$ & $($ IST $)$ & $(\mathrm{h})$ & $($ IST) \\
\hline Zenith & & & 1.55 & 24.56 & 0.90 & 25.10 & 0.77 & 27.16 & 1.31 & 27.80 \\
$15^{\circ} \mathrm{N}$ & & & 1.55 & 24.83 & 0.60 & 25.60 & 0.70 & 26.80 & 0.50 & 26.40 \\
$15^{\circ} \mathrm{S}$ & & & 1.31 & 24.50 & 0.90 & 24.76 & & & 0.90 & 27.76 \\
$15^{\circ} \mathrm{E}$ & \multirow{2}{*}{0.46} & 24.30 & 1.50 & 24.70 & 0.92 & 25.03 & 0.70 & 26.80 & 1.30 & 27.30 \\
$15^{\circ} \mathrm{W}$ & & & 1.55 & 24.83 & 0.90 & 25.00 & 0.77 & 26.96 & & \\
$30^{\circ} \mathrm{N}$ & & & 1.55 & 24.76 & 0.60 & 24.96 & 0.77 & 27.16 & & \\
$30^{\circ} \mathrm{S}$ & & & 1.55 & 24.70 & 0.92 & 24.90 & 0.70 & 28.56 & 1.10 & 26.96 \\
$30^{\circ} \mathrm{E}$ & 0.40 & 24.10 & 1.30 & 24.40 & 0.90 & 25.03 & 1.10 & 27.10 & 0.70 & 27.50 \\
$30^{\circ} \mathrm{W}$ & & & 1.55 & 24.93 & 0.90 & 24.90 & 0.65 & 25.40 & & \\
\hline
\end{tabular}

\subsection{Observations of 23-24 April 2009}

Figure 5 presents the intensity deviations and the results of wavelet analysis for 23-24 April 2009. The variations observed on this particular night were dominated by short period wave structures. The longer period nocturnal variations show minima to occur at around 2200-2300 $\mathrm{h}$ IST at all the zenith angles emphasizing the presence of a tide-like wave in the data. The left panel in Figure 5 plots the mean intensity deviations in zonal direction for zenith angles $30^{\circ} \mathrm{E}, 15^{\circ} \mathrm{E}, 0^{\circ}, 15^{\circ} \mathrm{W}$ and $30^{\circ} \mathrm{W}$ (from top to bottom), while the right panels show their corresponding wavelet spectra. One may note larger amplitudes of short period waves on this night compared to 21-22 April 2009. Also, in the wavelet spectra one may note clear signatures of wave phases to occur at different 
times for the data obtained at different zenith angles. Although, one can clearly note a phase propagation of waves in the data; as explained earlier, we carry out the best-fit analysis on the wave phases (time of maximum amplitudes) to estimate the zonal structures of observed waves in the data. Results of the best-fit analysis are shown in Figure 6. In this figure, solid squares show the observed phase of waves at $30^{\circ} \mathrm{E}, 15^{\circ} \mathrm{E}, \mathrm{Zenith}, 15^{\circ} \mathrm{W}$ and $30^{\circ} \mathrm{W}$ while, the solid red connecting lines show the best-fitted model. The results reveal that $0.4-0.5 \mathrm{~h}$ wave has a horizontal wavelength of $\sim 61 \mathrm{~km}$, while the $0.7-1.0 \mathrm{~h}$ and 1.1-1.5 $\mathrm{h}$ waves have their horizontal wavelengths $\sim 97 \mathrm{~km}$ and $105 \mathrm{~km}$ respectively.
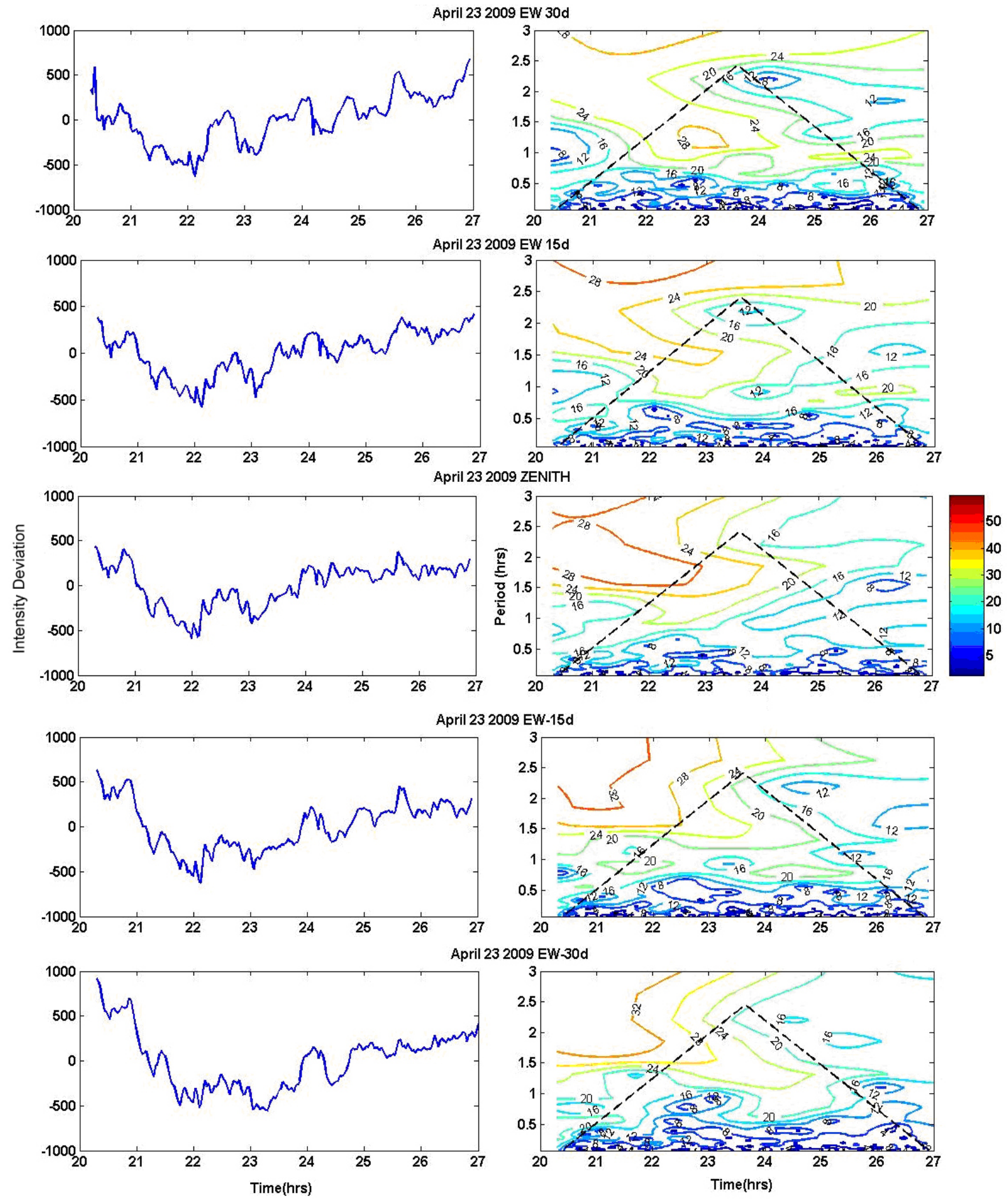

Figure 5. Same as Figure 1 but for the observations carried on 23-24 April 2009 


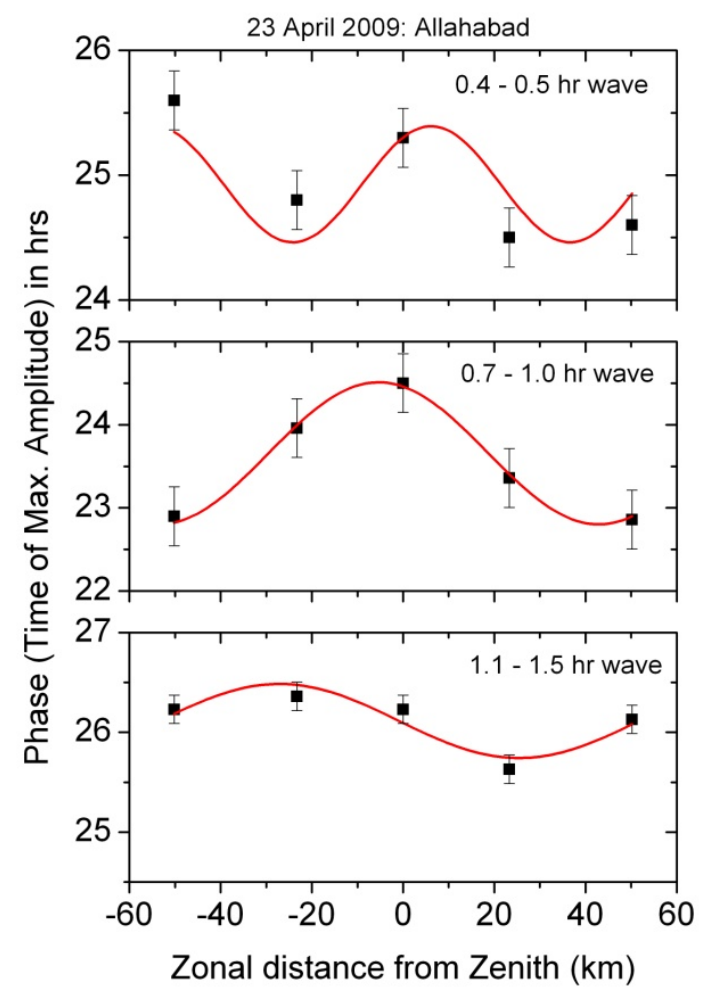

Figure 6. Same as Figure 2 but for the observations carried on 23-24 April 2009

The observed mesospheric $\mathrm{OH}$ intensity variability in meridional direction is shown in the left panels of Figure 7. Similar to the variability observed in the zonal direction, the long period tide like wave is noteworthy in data with minima at around 2200-2300 h IST. One may also note the similar wave modes extending from $30^{\circ} \mathrm{N}$ to $30^{\circ}$ $\mathrm{S}$ zenith angles. The right panels depict the results of wavelet analysis of the mean intensity deviation data. The short period wave features with periodicity 0.25 to $1.5 \mathrm{~h}$ are clearly noted in the data with their phase varying with zenith angles. For an estimation of meridional structures of waves, we plot the phase of wave packets with zenith angles in Figure 8 as solid squares. The best-fit cosine model results are shown as connecting red lines. The horizontal wavelengths in meridional directions are estimated to be $\sim 105 \mathrm{~km}, 55 \mathrm{~km}$ and $80 \mathrm{~km}$ respectively for 0.4-0.5 $\mathrm{h}, 0.7-1.0 \mathrm{~h}$ and 1.1-1.5 $\mathrm{h}$ waves. Table 2 summarizes the observed wave features for this particular night.

Table 2. Same as Table 1 but for 23-24 April 2009

\begin{tabular}{cccccccccccc}
\hline & \multicolumn{3}{c}{ 1st wave } & \multicolumn{2}{c}{ 2nd wave } & \multicolumn{2}{c}{ 3rd wave } & \multicolumn{2}{c}{ 4th wave } & \multicolumn{2}{c}{ 5th wave } \\
\cline { 2 - 12 } Directions & $\tau$ & $\mathrm{t}_{\mathrm{m}}$ & $\tau$ & $\mathrm{t}_{\mathrm{m}}$ & $\tau$ & $\mathrm{t}_{\mathrm{m}}$ & $\tau$ & $\mathrm{t}_{\mathrm{m}}$ & $\tau$ & $\mathrm{t}_{\mathrm{m}}$ \\
& $(\mathrm{h})$ & $($ IST) & $(\mathrm{h})$ & $($ IST $)$ & $(\mathrm{h})$ & $($ IST $)$ & $(\mathrm{h})$ & $($ IST $)$ & $(\mathrm{h})$ & $($ IST) \\
\hline Zenith & & & 0.30 & 22.93 & & & 0.46 & 25.30 & 1.55 & 26.23 \\
$15^{\circ} \mathrm{N}$ & 1.10 & 21.13 & 0.92 & 23.20 & 2.20 & 24.03 & 1.10 & 25.50 & 1.50 & 26.26 \\
$15^{\circ} \mathrm{S}$ & & & 2.20 & 22.96 & 1.45 & 23.23 & 1.10 & 25.60 & 0.77 & 26.23 \\
$15^{\circ} \mathrm{E}$ & 0.65 & 22.10 & 2.20 & 23.76 & 0.93 & 23.97 & 0.55 & 24.80 & 1.55 & 26.36 \\
$15^{\circ} \mathrm{W}$ & 0.92 & 21.70 & 0.77 & 24.50 & 0.92 & 23.36 & 2.20 & 24.80 & 1.10 & 25.63 \\
$30^{\circ} \mathrm{N}$ & 0.77 & 21.50 & 2.20 & 23.53 & 0.40 & 23.26 & 0.70 & 26.10 & 1.10 & 26.40 \\
$30^{\circ} \mathrm{S}$ & 1.85 & 22.06 & 0.40 & 22.10 & 0.55 & 23.63 & 0.92 & 24.50 & 1.13 & 26.60 \\
$30^{\circ} \mathrm{E}$ & 0.55 & 22.80 & 1.31 & 22.96 & 2.20 & 24.16 & 0.46 & 25.66 & 1.85 & 26.23 \\
$30^{\circ} \mathrm{W}$ & 0.90 & 22.86 & 0.30 & 24.46 & 2.26 & 24.50 & 1.85 & 25.50 & 1.10 & 26.13 \\
\hline
\end{tabular}



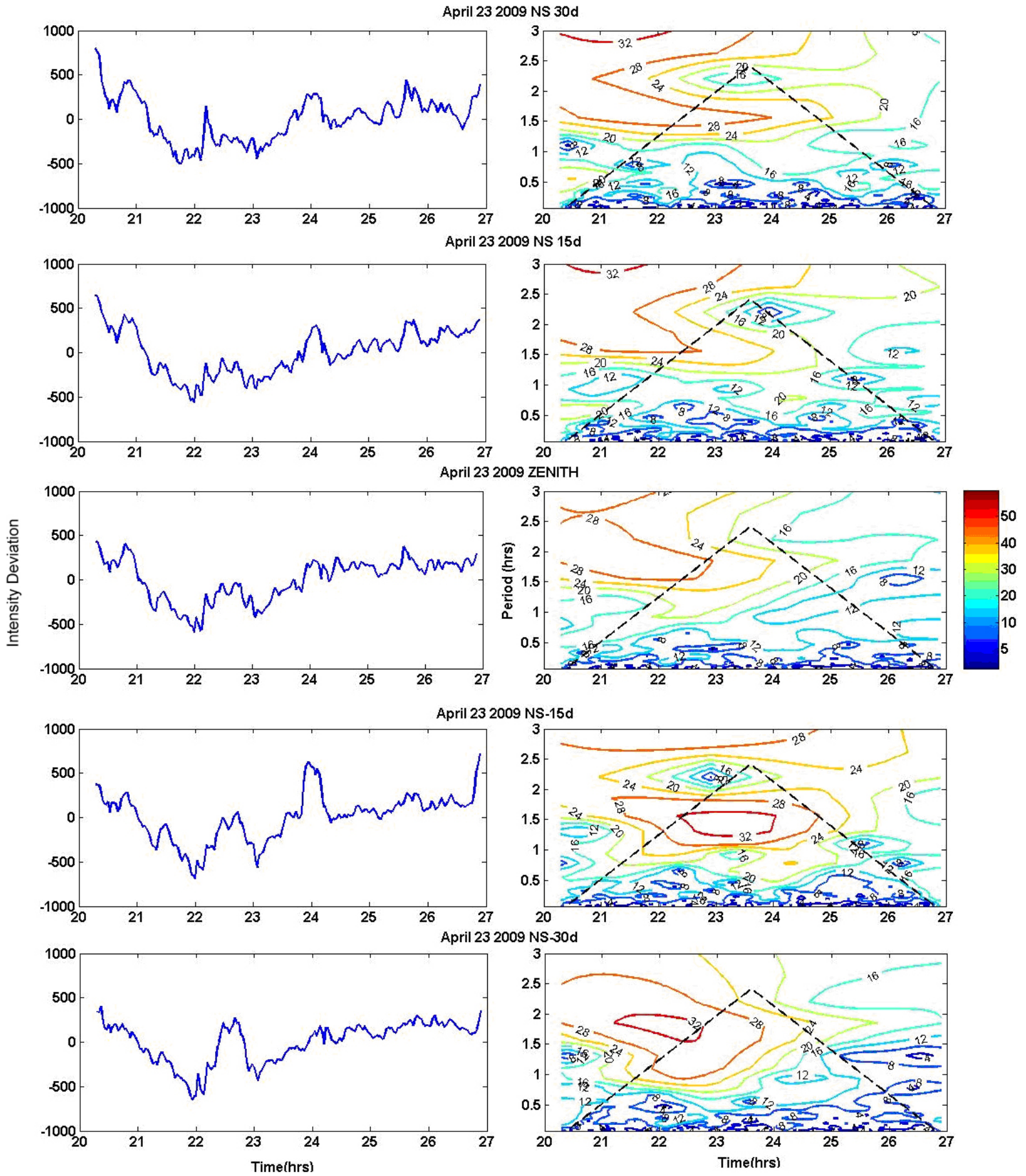

Figure 7. Same as Figure 3 but for the observations carried on 23-24 April 2009 


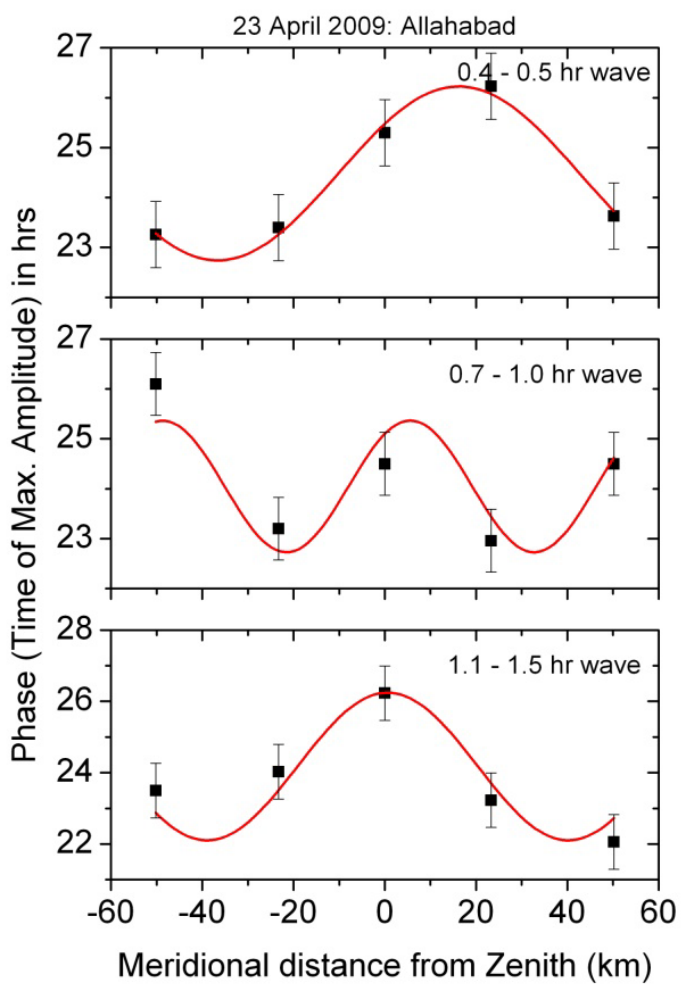

Figure 8. Same as Figure 4 but for the observations carried on 23-24 April 2009

It is important that the short period waves observed on 21-22 April 2009 as well as 23-24 April 2009 exhibit zonal as well as meridional structures. With aircraft-borne Michelson Interferometer measurements, it has been shown the zonal as well as meridional wavelength associated with short period gravity waves to be $\sim 41,65$ and $230 \mathrm{~km}$ in meridional directions (Espy \& Huppi, 1997). Our observations are important in terms of zonal momentum exchanges (Sato et al., 1999). It is well appreciated that the thermal structure (apart from the radiative balance) in the upper mesosphere is explained mainly by the existence of meridional circulation due to the gravity wave induced forces. The gravity waves propagating purely meridionally do not associate with vertical flux of zonal momentum, although they have a role in the momentum balance in the middle atmosphere. The waves observed in present investigation show zonal as well as meridional structures and as the meridionally propagating waves with non-zero zonal components are important for the meridional distribution of vertical flux of zonal momentum (Sato et al., 2003), the present observation has an importance. This is further substantiated because the departure from the gradient-wind balance may possibly due to the dissipation of gravity waves and tides with associated vertical flux of meridional component (Liberman, 1999). Although the present study is a limited attempt; a wider study is in progress to achieve a suitable statistics on the short period waves and their zonal and meridional structures which will be important for the global circulation of middle and upper atmosphere.

\section{Conclusions}

Imaging observation of $\mathrm{OH}$ nightglow has been made at Allahabad $\left(25.5^{\circ} \mathrm{N}, 81.9^{\circ} \mathrm{E}\right)$, India during April 2009. In understanding the role that gravity waves play in the MLT dynamics, the observations of zonal and meridional structure of short-period gravity waves are considered important. Herein, the concurrent measurements of horizontal wavelengths and periodicity of gravity waves on two nights (viz. 21-22 and 23-24 April 2009) has been presented. Morlet wavelet analysis of the intensity data was performed to identify the wave packets present in the data, and mainly three distinct wave packets having period in the range of (i) $0.4-0.5 \mathrm{~h}$, (ii) $0.7-1.0 \mathrm{~h}$ and (iii) 1.1-1.5 $\mathrm{h}$ were present. The horizontal wavelength of these observed wave packets lay in the range of 55-199 $\mathrm{km}$. In the South American sector, Medeiros et al. (2005) found the horizontal wavelength varying from 15 to 35 $\mathrm{km}$, while Wrasse et al. (2006) reported the horizontal wavelengths ranging between 5 and $30 \mathrm{~km}$ for $5-10$ minute waves. In future, a comprehensive study featuring short-period gravity waves will be performed with a bigger database encompassing several nights to understand the gravity wave-MLT circulation interconnection. 


\section{Acknowledgements}

The present work is supported by Dept of Space and Dept. of Science and Technology, Govt. of India. The study undertaken is a part of CAWSES India Phase II Programme - Theme 3 initiatives.

\section{References}

Das, S. K., Taori, A., \& Jayaraman, A. (2012). On the role of dust storms in triggering atmospheric gravity waves observed in the middle atmosphere. Annales Geophysicae, 29, 1647-1654. http://dx.doi.org/10.5194/angeo-29-1647-2011

Espy, P. J., \& Huppi, R. (1997). The intertropical convergence zone as a source of short period mesospheric gravity waves near the equator. Journal of Atmospheric and Solar Terrestrial Physics, 59(13), 1665-1671. http://dx.doi.org/10.1016/S1364-6826(96)00165-4

Forbes, J. M., \& Wu, D. (2006). Solar tides as revealed by measurements of mesosphere temperatures by the MLS experiment on UARS. Journal of Atmospheric Sciences, 63, 1776-1797. http://dx.doi.org/10.1175/JAS3724.1

Fritts, D. C., \& Alexander, M. J. (2003). Gravity wave dynamics and effects in the middle atmosphere. Reviews of Geophysics, 4l(1), 1003. http://dx.doi.org/10.1029/2001RG000106

Guharay, A., Taori, A., \& Taylor, A. (2008). Summer-time nocturnal wave characteristics in mesospheric $\mathrm{OH}$ and $\mathrm{O}_{2}$ airglow emissions. Earth Planets Space, 60, 973-979.

Hines, C. O. (1960). Internal gravity waves at ionospheric heights. Candian Journal of Physics, 38, 1441-1481. http://dx.doi.org/10.1139/p60-150

Lakshmi Narayanan, V., Gurubaran, S., \& Emperumal, K. (2010). Airglow imaging observations of small-scale structures driven by convective instability in the upper mesosphere over Tirunelveli $\left(8.7^{\circ} \mathrm{N}\right)$. Journal of Geophysical Research, 115, D19119. http://dx.doi.org/10.1029/2009JD012937

Liberman, R. S. (1999). The gradient wind in the mesosphere and lower thermosphere. Earth Planets Space, 51, 751-761.

Medeiros, A. F., Takahashi, H., Buriti, R. A., Pinheiro, K. M., \& Gobbi, D. (2005). Atmospheric gravity wave propagation direction observed by airglow imaging in the South American sector. Journal of Atmospheric and Solar Terrestrial Physics, 67(17-18), 1767-1773. http://dx.doi.org/10.1016/j.jastp.2005.03.015

Mukherjee, G. K., Pragati Shikha, R., Parihar, N., Ghodpage, R., \& Patil, P. T. (2010). Studies of the wind filtering effect of gravity waves observed at Allahabad $\left(25.45^{\circ} \mathrm{N}, 81.85^{\circ} \mathrm{E}\right)$. Earth Planets Space, 62, 309-318. http://dx.doi.org/10.5047/eps.2009.11.008

Parihar, N., Gurubaran, S., \& Mukherjee, G. K. (2011). Observations of OI $557.7 \mathrm{~nm}$ nightglow at Kolhapur (17 N), India. Annales Geophysicae, 29(10), 1873-1884. http://dx.doi.org/10.5194/angeo-29-1873-2011

Sato, K., Kumakura, T., \& Takahashi, M. (1999). Gravity waves observed in a high resolution GCM simulation. $\begin{array}{lllll}\text { Journal of Atmospheric } & \text { Sciences, } & 56, & 1005-1018 .\end{array}$ http://dx.doi.org/10.1175/1520-0469(1999)056<1005:GWAIAH >2.0.CO;2

Sato, K., Yamamori, M., Ogino, Shin-Ya, Takahashi, N., Tomikawa, Y., \& Yamanouchi, T. (2003). A meridional scan of the stratospheric gravity wave field over the ocean in 2001 (MeSSO2001). Journal of Geophysical Research, 108(D16), 4491. http://dx.doi.org/10.1029/2002JD003219

Scheer, J., \& Reisin, E. R. (2010). Statistical properties of nonlinear wave signatures in OH and O2 airglow brightness data observed at lower mid latitudes. Journal of Atmospheric and Solar Terrestrial Physics, 72, 588-594. http://dx.doi.org/10.1016/j.jastp.2010.02.015

Shiokawa, K., Ejiri, M. K., Otsuka, Y., Ogawa, T., Kubota, M., Igarashi, K., ... Nakamura, T. (2000). Multi-point observation of short-period mesospheric gravity waves over Japan during the FRONT campaign. Geophysical Research Letters, 27(24), 4057-4060. http://dx.doi.org/10.1029/2000GL011917

Smith, S. M., Scheer, J., Reisin, E. R., Baumgardner, J., \& Mendillo, M. (2006). Characterization of exceptionally strong mesospheric wave events using all-sky and zenith airglow observations. Journal of Geophysical Research, 111, A09309. http://dx.doi.org/10.1029/2005JA011197

Taori, A., \& Taylor, M. (2010). Dominant winter-time mesospheric wave signatures over a low latitude station, Hawaii $\left(20.8^{\circ} \mathrm{N}\right)$ : An investigation. Journal of Earth System Science, 119(3), 259-264. http://dx.doi.org/10.1007/s12040-010-0020-y 
Taori, A., \& Parihar, N. (2011). Simultaneous bi-station measurements of mesospheric waves from Indian low latitudes. J. Advances in Space Research., 48, 218-226. http://dx.doi.org/10.1016/j.asr.2011.03.026

Taori, A., Raizada, S., Venkat Ratnam, M., Tepley, C. A.., Nath, D., \& Jayaraman, A. (2012a). Role of tropical convective cells in the observed middle atmospheric gravity wave properties from two distant low latitude stations. Earth Science Research, 1(1), 87-97.

Taori, A., Kamalakar, V., Raghunath, K., Rao, S. V. B., Wu, Q., \& Russell III, J. M. (2012b). Simultaneous Rayleigh lidar and airglow measurements of middle atmospheric waves over low latitudes in India. Journal of Atmospheric and Solar Terrestrial Physics, 78-79, 62-69. http://dx.doi.org/10.1016/j.jastp.2011.06.012

Taori, A., Taylor, M., \& Franke, S. (2005). Detection and measurement of a terdiurnal wave signature in the upper mesospheric temperature and wind fields at low latitudes $\left(20^{0} \mathrm{~N}\right)$. J. Geophys. Res., 110, D09S06. http://dx.doi.org/10.1029/2004JD004564

Wrasse, C. M., Nakamura, T., Takahashi, H., Medeiros, A. F., Taylor, M. J., Gobbi, D., ... Admiranto, A. G. (2006). Mesospheric gravity waves observed near equatorial and low-middle latitude stations: wave characteristics and reverse ray tracing results. Annales Geophysicae, 24(12), 3229-3240. http://dx.doi.org/10.5194/angeo-24-3229-2006 